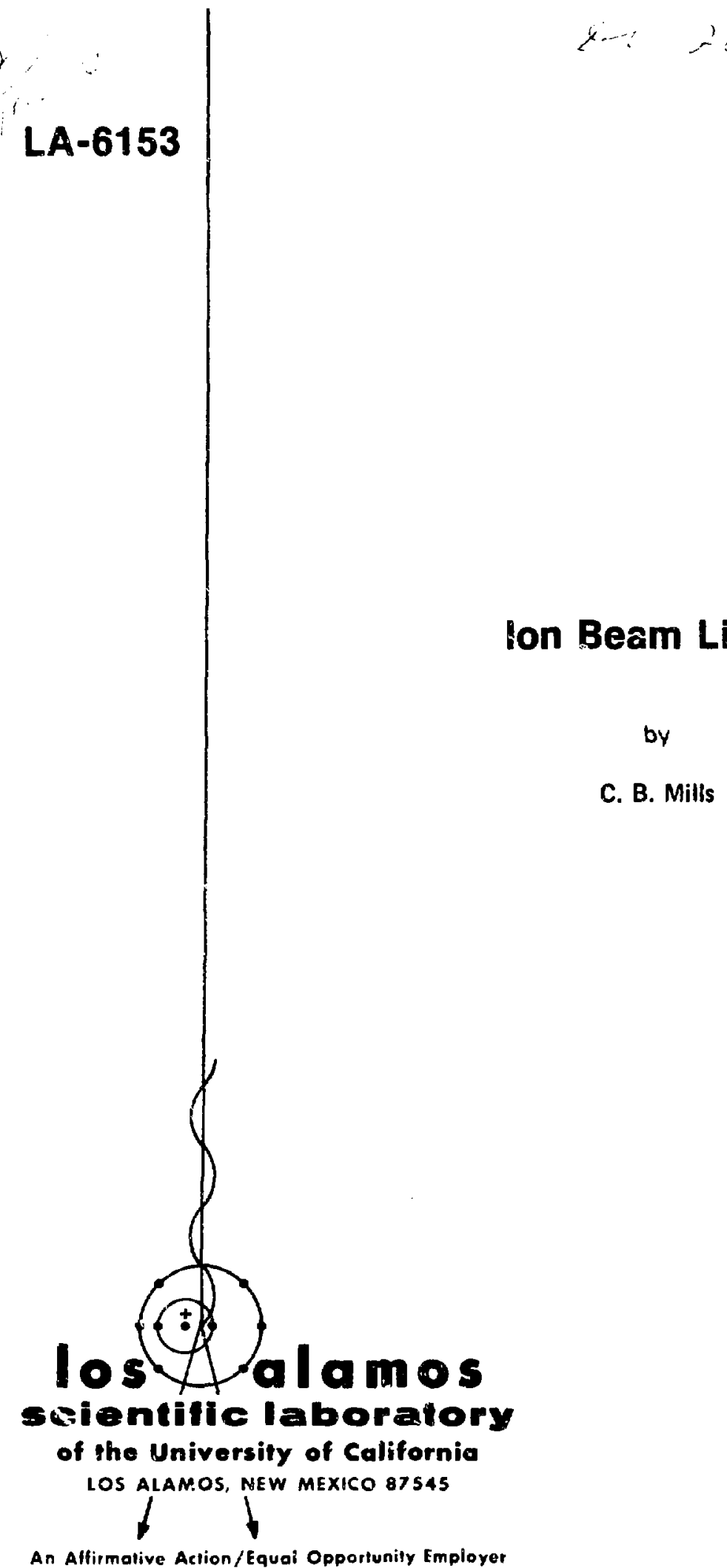

UC-34d

Reporting Date: Octsber 1975

Issued: February 1976

\title{
Ion Beam Limits
}

by

C. B. Mills 
Printed in the United States of America. Available from National Technical Information Service

U.S. Department of Commerce

S285 Port Royal Road

Springfield, VA 22151

P-ica: Printed Copy $\$ 4.50$ Microfiche $\$ 2.25$

Thin report was prepared an an acrount of wark sponeored

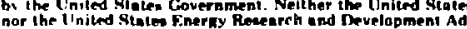
miniatrulian, nor $a n y$ of theli employese. nur anu of their ron.

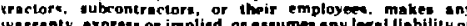

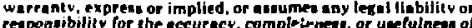

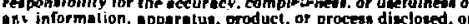
reprearnls that its uze would not infriphe privately oened rixhts. 
ION BEAM LIMITS

by

C. B. Mills
The report was piepurice

Sponkored by the Utruted Staites an account of wan the United Stater nor the United Stutes Nesther

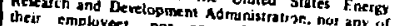

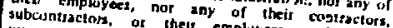
warranty, express of thes empluyess. makes ony

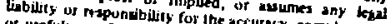
of unefulnew of any information, appoty, conpleteress process discluiced, os represtents, apparatu, product ot infinge privately awned nghts.

\begin{abstract}
The cooperative physical processes of ion source and ion beam physics in magnetic fields can be separated into plasma internal motions, motion from the source plasma into the beam, and beam formation. A few experiments demonstrate that these processes are consistent with elementary lav's of charge diffusion. Ion beam current limits are almost independent of magnetic field and have magnitudes consistent with classical diffusion processes. Ion current is proportional to applied potential gradient up to high voltage breakdown values which are determined by electrode geometry and secondary electron currents. Beam plasma stability, which is resessary for isotope separation using ion beam technology, depends on the formation of a dense, chargeneutralizing plasma as well as on ion source stability.
\end{abstract}

\section{INTRODUICTION}

High current ion heams ar' accelerated from dense electronic plisma hy high gradient elec. trostatic fields. Sipparation of different ion species of' jotopes in quantity has been accomplished by focusing these high current ion beams in magnetic fields. The steps in this process are (1) formation of a dense ion plasma. (2) acceleration of these ions from the surfice (meniscus) of the plasisma by a carefully optimized system of electrodes at high porential. and (a) nevtralization of the ion beamplasma charge forces to permit lixing of ion trajectory.

This study of ion heam limits was made' in connection with the large isotope scparation faceility the (alutron) all (bak Ridge. TN. which was under the general direction of lis. 0. Liawrence. Sicedess of that facility in producing large quantities of thitl from uranium is che to the st ability and repreducibility of the ion heam dissemblies. This report discusses the nature of those beams and the ion current limiting processes in them.
The different kinds of ion sources-whether devoloped by high voltage spark. direct current are. electromagnetic induction, potential traps in a magnetic field. or clectron beam currents impingingr (II) a gis--are all similar in structure for high ion density because of the very small energy equilibration time in dense plasma. Moreover, the ambipolar diffusion forces are relatively large in all of these ion witurces. and the discharges may be considered to be quiescent. hence the following remarks pertain "w all types of gaseous elect ronic plasma.

Filectrostatic fields applied to the surface of a dellse plasma cannot penetrate into the body of the planmat. Thus the interaction between appliod putential and the plasma surface which produces the ion heam is given by a Poisson equation in which the electron number density is a function of electron templemiture, which can be much higher than ion temperature. This is unlike the simpler solution of the cullattion which gives Child's law as the connectim between current. potential drop, and plane electrode spacing. Composit ion of the ion and gas stream crossing the plasma surface is given to the first order 
by Saha's equation for ionic species except when interaction hetween the applied potentiai and the electron beam used for plasma ionization hegins to cause instabilities. In casies where the cotal ion current as well as its uniformity and stability are to be maximized, the area of the ion source. the potential gradient ( $\mathrm{V}^{3 / 2} / \mathrm{d}^{2}$ in Child's law). and the numerous causes of elect rode erosion and ion heam instability must be studied. Efficiency of plasma ionization and ion beam arceleration are generally consistent with optimum overall performance because of the large magnitude of energy dissipation in high current ion sources. It has been found that plasma uniformity and ot her aspects cont rolling ion source performance are optinized by the use of a high magnetic field in the ion source and heam regions. In the Calutron, this fietd i. also used to focus different isotopes at the $1811^{\circ}$ point in an almost semicircular trajectory.

The ion source under consideration uses a hot cathode as a high current electron source to ionize a gas in an adjacent chamber. The assembly is in a high magnetic field (800) Oe): one side of the chamber is open to a high potential gradient set up by $6011120 \mathrm{kV}$ applied to an electrode assembly (Fig. 1). Figure 2 shows a cross section of the ion source and electrode geometry used on control ion current and beam divergence. The mannetic field is parallel to the $x$-axis in Fig. 1 and normal to the plane of Fig. 2.

Consistent with the space charge limit in the acceleration region. the ion beam is largest when the degree of ionization. pressure. and potential gradients are untimum for an innic species over the largest possible plisma surface area exposed to the accelerating voltage. These are optimum when the power source is userl most efficiently. as the sonurce of ionizing electrons has its own limitations and the largest enerer sink is that due to ridiative transter and escape of energet ic electrons. This has resulted in the use of a high magnetic field for the most intense sources of useful ior: beams. The ions in the

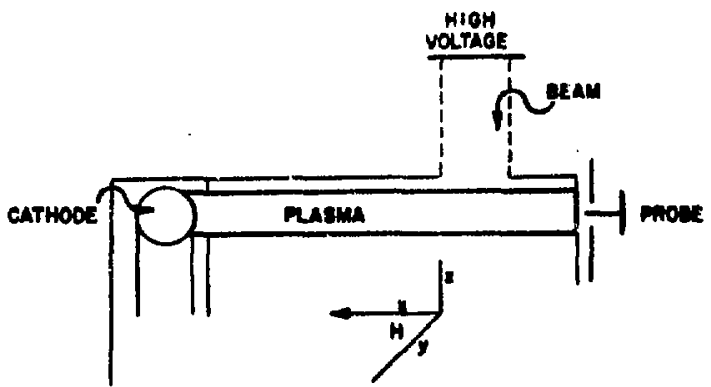

Fig. 1.

Gometry' of plasma probe experiment.

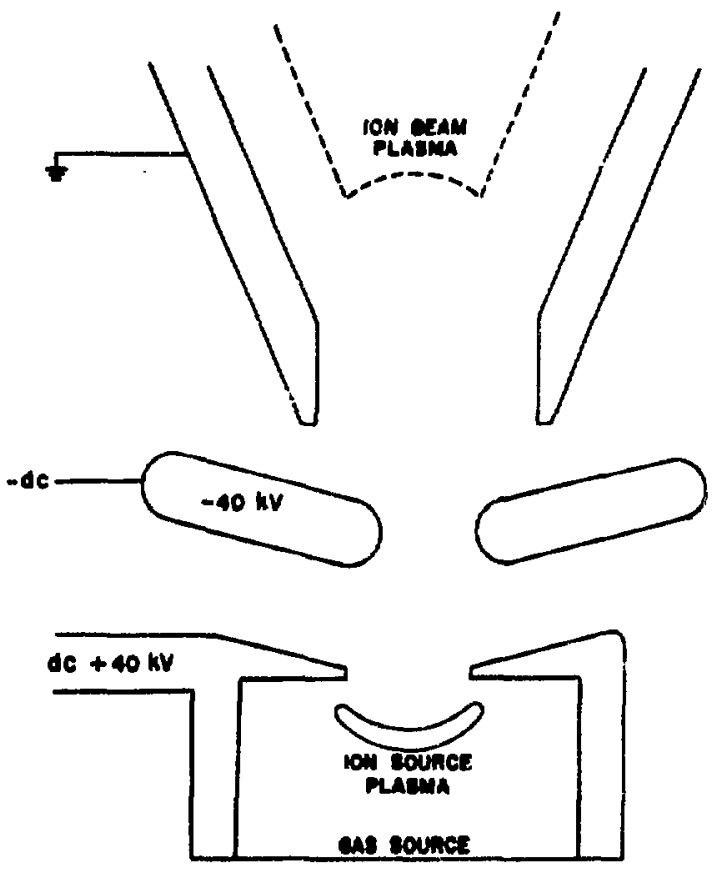

Fig. 2.

A tupical high density ion beam geometry, the Inicersity of California Calutron.

plasma are normally accelerated along an internal electric ficld $E$ normal in the magnetic field $H$ but with a net flow normal to $E$ along a cycloidal path to the surfince of the plasma. Loss of elect rons by diffusion normal to a magnetic field may ordinarily he considered small. The third direction. along the mugnet ic lines of flux. ('an easily be transformed int" an electron trap by inserting a negative potential or an insulated surface at each end. This also increases the plasma uniformity by redlcing potential and densily gradients from the electron source toward the anode.

Note that electrons must still have an easy mode of egress from the plasma in a magnetic field because the electron current is the source of power. In either the oscillating volume or electron beam power sources, electrons are injected into the hody of the arc along $H$; therefore an equal elec son current, plus the negative charge equivalent of the useful positive charges diffusing out of the plasma, must leave the arc to maintain a stationary concition. Otherwisc. the arc will discharge itself hy high frequency, mandom oncillations called "hash." which increase tho electron diffusion rate across $\overrightarrow{\mathrm{H}}$. This mechanism has heen commonly conceived to be the only mode of 
egress and is the process effective in the "Bohm limit" for transverse currents. Howcver, the transverse diffusion velocity on equipotential surfaces, related te the normal velocity by the product of the Larmor frequeney a and the collision period $\tau$. can be sufficiently high to permit the develupment of stationary electron flow patterns from anv point in the arc directly to the high density plasma boundari, where a quicesent current of elect rous parallel ta H? becomes possiblo.

The following discussion presents the ion beam problem in three parts and describes a funclamental isprest of each. Section Il discusses the source plasma. Sec. III ion beam formation. and Siec. IV the acreleration region. Sertion $V$ compares ions currents alling and across the magnotic field.

\section{INTERNAL STHICTURE OF AN ION SOURTE PLASMA}

'The interaction of a st ream of electrons from a hot cothude and a molecular gas evapurated from a briler at a density of approximatcly $10^{1: 3}$ porticles/ml results in excilation and ionization of the gats and thermalization of the electroms to a comperature determined by energy balance

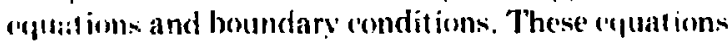
are well known: the boundary conditions are indirodly defined by neasurement of total ion heam misnitude and stability (determined at a remote fincus of the ion beam). These gross incisuremonts are madro in addition to gas flow rate and electron corrent and catthude purent ial. but plasmat and heam prowesises must be determined by inore detailed sturlies for which the langmuir probe is useful.

It is well known'-1 that a magnetic field callmon change the particle velocity distribution function. however it doses introduce large drift velucity efual II $\cdot \cdot \mathrm{H} / \mathrm{H}$ acrosis the magnetic field $H$ in intential eradient E. The drift velocity is nommal $10 \mathrm{H}$. therofore a probe surtine which is also normal to $\mathrm{H}$ and properly shielded will measure onls the current

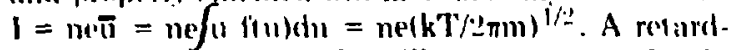
ing pulcontial ${ }^{\prime}$ on a prohe will permit current $I=l_{\text {" }}$ exple -ev/k'T) oo flow to its surfine. and the variation

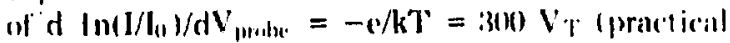
units) measures (harge temperalure $\mathrm{k} T \%=V \mathrm{r}$ in elecelron volls. In addition. the plasma denvity $n$ is determined from the same equation lopicubel $=n e\left(1 \cdot V_{r} / 2 \pi m\right)^{1 / 2} \exp \left(-V_{0} / N r\right)$ for 1 measured at $V_{11}=0$. i.e., al plasmn polential. Thus. $n=3.71$

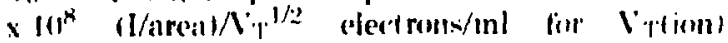
« Vir (electron).
Interpretation of probe measurements at the anode ond of a plasma lor current fliswing along the mignetic field is simplifier is noting the wear pattern on the walls of the ion rhamber. Figure :? shows a simplified sketch of plasma elect ron motion in the bodv of the high density plasma used in this studv. In the $W$ direction in Fig. 4, probe moisurements show electron concentration number density) and temperature. Note that the plasma distribul ion in space, assumed from the wear pattern. is su;porled by the measurement of the cuncentration distribution ac rosis the plasma. The negative side of the probe position supplies the cold gas input. As the electrons drift, the concent ration increases, moving the electronic plasma radially away from the collimated oleetron beam source. as shown in Fig. 3. On the side toward the meniscus, the drift current adds is the primary electron current to form a max. imum in number density. The electron temperature increases in similar fashion. but with a strong docrease near the plasma sheath, or menisc'us, due to processes (such as $\mathbf{H}$-directed electron drain 10 chamber walks and interaction with the iu, boam) that increase the rate of energy losis. This fact is demonstrated hy Fig. 5 which shows the effect of ion heam acceleration fields on the internal plasma potcintial. Clearly. the direction of elcetron drift changes with the sign of $\mathrm{E}$ in the drif velocily formulat $\mathrm{s}=(\mathrm{E} / \mathrm{H}$, where $\mathrm{E}=-i \mathrm{~V} / \mathrm{d})$. The magnitude if $\mathrm{F}$ (from Fig. 5) is approximately $60 \mathrm{~V} / \mathrm{cm}$. the polontial at plasma center $4.3 \mathrm{~V}$. and the plasma thickiness $11.26 \mathrm{~cm}$.

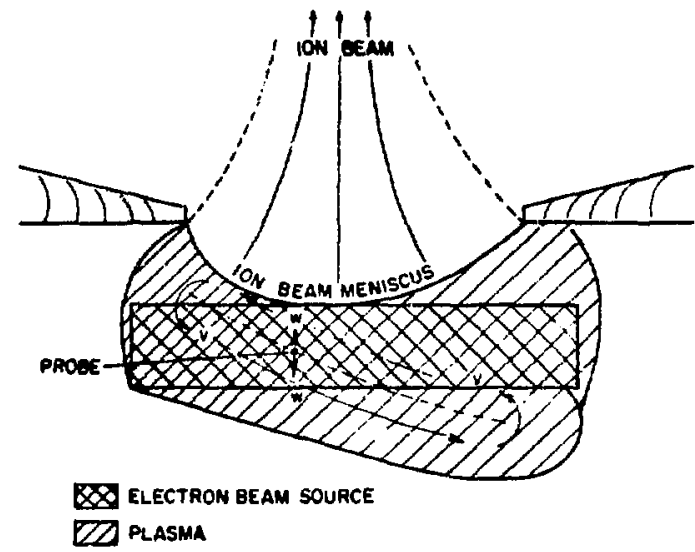

Fig. is.

Irm transwerse and nirmal motion in the plasma, both perpendicular to the magnetic firld. 


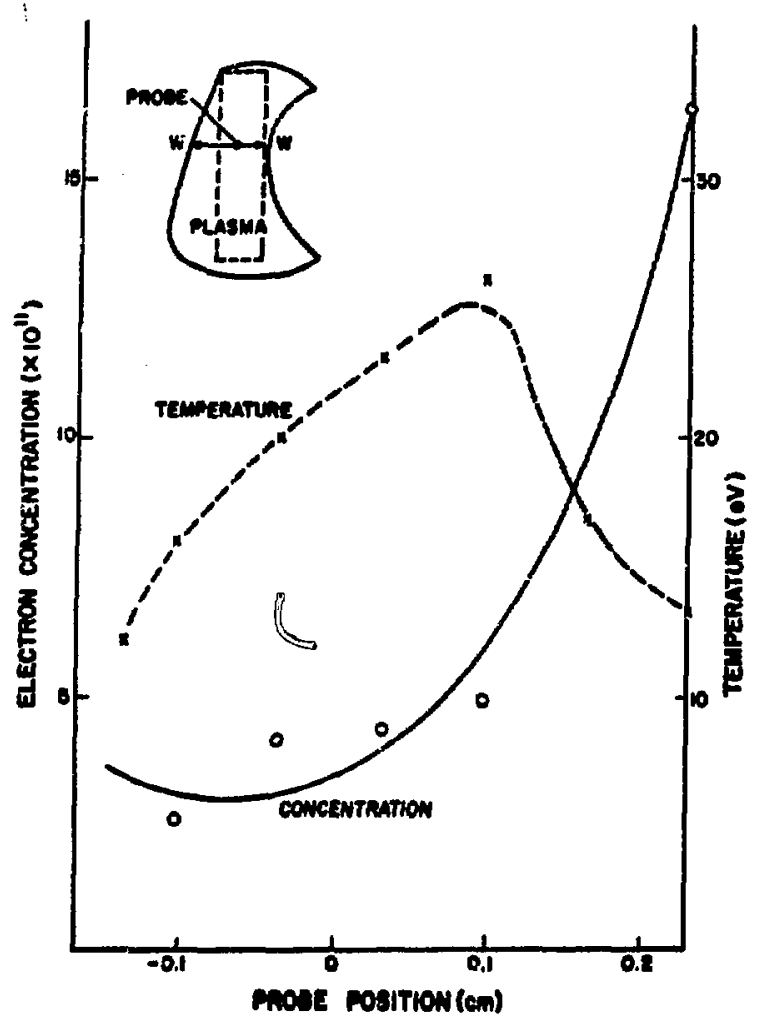

Fig. 4.

H!ectrun concentration and temperature across thr arson plasma.

Inn current from the plasma sheath must he eyual I11 ion heam current. It is given by $I=n c \bar{w}$ wherc. according to Chapman and Cowling." the diffusion velocity $\omega$ is given by

$$
\bar{\omega}=\left(\frac{\mathrm{CE}}{\mathrm{m}}-\frac{1}{\mathrm{~nm}} \cdot \frac{\partial \mathrm{p}}{\partial z}\right) \frac{\tau}{1+\omega^{2} \tau^{2}} .
$$

The terms are conventional and $i$ is the ion-ion collision period, i.e.. the mean time for an ion to accumulate a $90^{\circ}$ deflection by Coulumb collisions. This was given by Spit zer ${ }^{4}$ as

$$
T=\frac{11.4 A^{1 / 2} T^{3 / 2}}{n Z^{4} \ln \Lambda}
$$

Ion-elect ron collisions are less effective in promonting diffusion by one ordor of magnitude.

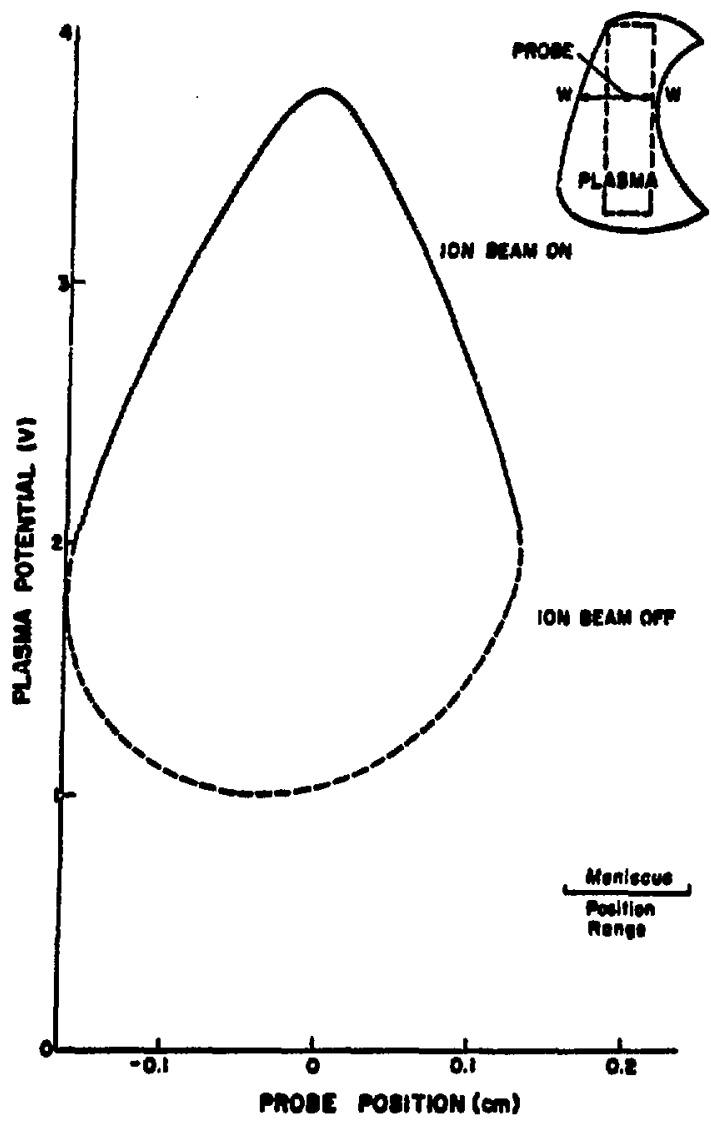

Fis. 5.

Plasma potential us probe position.

Probe measurements permil a dired test of ion diffusion rate calculations. Figure 4 inagniturles are consiat ent with a mean collision period of $4 \times 10^{-5} \mathrm{~s}$ and, comparing putential and pressure gradient terms in the diffusion velocity, the potential term denominator. Then $I_{w} \approx 4.1 \mathrm{ma} / \mathrm{cm}^{2}$ for the measured condilions in which $n=1.6 \times 10^{12}$. $\mathrm{F}=0.2 \mathrm{esu} / \mathrm{cm}^{\mathrm{m}}, \tau=4 \times 10^{-5} \mathrm{~s}$, and $\omega=1.6 \times 10^{\circ}$ $\mathrm{rad} / \mathrm{s}$. A lower limil to ion temperature of $0.1 \mathrm{eV}$ reduces $\tau$ to $3 \times 10^{-8} \mathrm{~s}$ and increases $I_{w}$ to 17 $\mathrm{ma} / \mathrm{cm}^{2}$. Experiment showed that the ion beam current across the plasma sheat h near the probe was $7.0 \mathrm{ma} / \mathrm{cm}^{3}$. This agreement was cunsidered excellent.

'J"he transwer'se velocity $v=\mathrm{cE} / \mathrm{H} \simeq 10^{13}\left(\mathrm{~m} \mathrm{~s}^{-1}\right.$ plays an import ant part in plasma dingnost ic's if the motion of ions aud clocel rons on these equigurential surfinces moves the individual charges vory ofuickly 
acruss $H$ to the emit ting surface of the plasma and to a position where the olectrons can move along $H$ to an electrode immediately on formation. as is avidently the catse. Bucanse of the presence of the electric gradient $E$, the charge's will clearly mowe from any point in the plasma loward the outer sur lince an an equipotential. The very asymmet ric densitv dist ribution which was experimentally observorl for the body of the plasma indicates that. in fact. there is a very small number of transits aroment the plasma. It is possible that there is only one transit fio ions liomed upun entrane into the wery hol plasma on the side awny from the ion beam emitting surfare. Thus the residence time for a charge is of the order of $10^{-i}$ s. smill with respect to the thermisl equilibrium time of ions and electrons of abrut $10^{-4}$ s (Ro... 4, p. 80).

A "streaming" motion normal to $H$ and $E$ (aibur ecquipotential surfaces) with a velonity $r \mathrm{~F} / \mathrm{H}$ will supply the ion loram meniscus with a sulticient guantity of ions to he consistent with the iun beam current if the effertive collision period is indeed of the order of the values consistent with the soll:collision time of spitzer." The physical situmion is more complex than the axsumptions in spilgers malysis. herause the geumetry of the plasma. instead of being effectively infinite fas in strllar phosics), is such that a single eloloidal path may cross the plasma radius from zero to lange clectric grarlient values. An ion on the poriphery of the plasma will leave the plasma in times of the order of fractions of microseconds ffractions of a perited $1=1 / w)$. 'This being so. and ion mormal diffusion bo. ing verv small acroms the miclplance of the plasma.

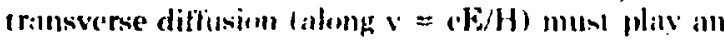

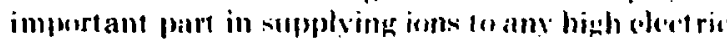

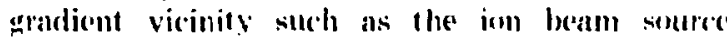
meniscus. Note that the mean ion energy in the

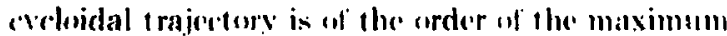
displacement $d=2\left(0 \mathrm{~F} / \mathrm{me}^{2}\right.$ ' times the electic

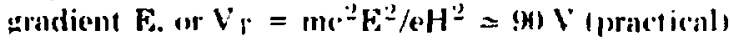
lint the upper limit of mean ion conereg for an infinite. geomet ry and a low ion-ion collision silse. The potential distribut ion in the plasima must provide in im. portant diffusion merhamism lor the ions.

A validation of the ion temperallure covaluation

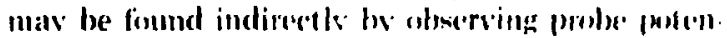
tial for the sero net corrent comelition. For this. $I=0$. or $I_{1}=I_{1}$. Thuss.

$$
\frac{n e \bar{c}_{1}}{4}=\frac{\text { ne } \bar{c}_{e}}{4} \exp \left(\frac{-4 V}{k T}\right) \text {. }
$$

(31'

$$
\bar{c}_{1}=\bar{c}_{e} \exp \left(\frac{-e V}{k T}\right)
$$

where subscript I signilies ion and e electron. Let $V=V_{n}=170 \mathrm{~V}$, an average probe potential for $I=0$. Since $k \bar{T}_{\mathrm{e}} \approx 20 \mathrm{eV}$ fior the plakma disceusised alowe. and since

$$
1 / 2 M \overline{c_{l}^{2}} \approx \frac{M}{m} \overline{c_{e}^{2}}\left(\frac{-2 V_{p}}{V_{e}}\right) \text { from } I_{e}=I_{J},
$$

then

$$
V_{1}=\frac{M}{m} V_{e} \exp \left(\frac{-2 v_{p}}{v_{e}}\right) \approx 0.1 \mathrm{eV}
$$

$V_{1}$ is ion temperature, $V_{e}$ elect ron temperature. and $V_{p}$ probe potential for $I_{e}=I_{L}$.

This rolationship is very sensitive to prohe poten. tial and electron temporature. The mean ration of $V_{1} / V_{t}>5$ for the ratio of fiosating probe potential in electrorn comperature in high density ion sources is commonly found in these high density ion sources.

\section{A. Discussion}

The diffusion of low temperature ions out of an electronic plasma cannot be constrained by a masurtic lield $H$ with an effectively very small founlombl wollision period because normal ditfision processes will oncur. If the geometry is such that the magnetic field serves to establish a potential mpadiont $E$, then ions and elect rous will move normal to $H$ and $E$ with relative freedom. Flect rons have such a very small cycloidal amplitude that they are rolitively immobile along the $E$ vector in spite of a shint coulomb). collision period. Because of the mativo immohility of electrons. as compared to ions. for mosion across equipotential surfiaces, the most stalhe high density plasma should be more negritive in the renter tsee "irm beam sfe" ralse in Fig. i) and should bo subject to foresed oscillations it al high oncrogy electoon stream. entering the phisma lakong $H$ ) to provide an energy source. does not have a stable mode of egress. Both of these situations have becoll observed in this and assencialled studios. In fan't. lhe channg in direction of internal plasmat currents. 
upon initiation of plasina hash. has an easily observed effect on ion beam trajectury from the inn source meniscus due to movement of the plasma sheath from more (less) to less (more) concave on the two sides (refer to Fig. 3).

Other means of exciting the discharge were devoloped in light of the alove considerations. An rf discharge using only the magnet ic component of the assembly shown in Fig. I formed a plasma of the same order of magnitude of density as the de eleciron heam most frequently used which has already be'n discussed. 'The geometry was simply that of' an induction coil whose current flows along the magnetic vector $H$ in vacuum. with a gas-filled discharge chamber immediately juxtaposed. Again. an extension of the Penning ion gage geometry (with a thermionic cathode heated only by the discharge but with a geometrical cross section permitting stahility in the sense discussed ahove) gave a very high densi. w. stable discharge that was used ${ }^{5}$ for ion beam production in the ampere range. Again, a high vollage, high rurrent spark with an uscillating volume geometry gave a high current (16 A) pulse of ions for use in a crvelot ron."

\section{B. Conclusions}

1. The transverse comporent of velocity $y=\omega r w$ is a major component on plasma drift across a magnetic field.

2. Stability, as a characteristic of ion sources re. quired for ion bean focusing (small intermal clectric gradients). does not limit ion source production. since st ability is comsistent with high density plasma formation with atteñt ion to eloctric fields which ars plasma boundary derived.

3. The Chapman and Cowling equation'? for ion drift velucity is consistent with electronic plasimn motions.

\section{ION BFAM FORMATION}

lons are formed in the ion suurce plasmal and presisented on tho nocinisciss elect ric araclionts af the i.m beam source. Hore, in plane geometry for onc chiarge species. ('hild's law relates ion courent I lo" accelcrating voluge $V$ and electrude spacing I $=\left(1, V^{i / 2} d^{-2}\right.$.

In the magnetic lield. the meniscus st ructure is complicated by in and eloctron density gladionts which. by l'oissons"s equation. aflect ion cournents. 'The magnitucle of tho effect on the ion currents which are space charge limited. due lo the presenese of a velocily distribution. may be seen to depend more on ion temperature than meniscuss structure. Since there is an uncertainty connected with this vicinity because of the possibility of effectively high ion temperatures (which are comparable with the kinetir energy change in a crcloidal path of amplitude $V_{V}($ ion $\left.) \sim E d=2 E^{2} / \mathrm{m}^{2}\right)$ it is necessary to lork for effects due to high ion temperatures, effeclive (resulting from a large cycloidal amplitude) or real.

The grosis effects of ion and electron temperature on ion beam formation are relatively simple (4) evaluate if there are only very small amplitude tran. sients, ard if secondary effects, such as thermionic emission from the material containing and probing the plasma, are small. The particle temperature effects can be shown to he relatively small, wit hout sufficient analytical knowledge of the plasma, if Child's law (which assumes zero initial velocity). derived from the simple Poisson equation, holds. Measurements can be made of a net current through high voltage electrodes from the meniscus in a direction normal to the magnetic field, and the "dark spare" between low voltage electrode and plasma parillel to the magnetir lield. "l'hese were made in a relatively st raight forward way which will not be discussicd here. One interesting difficulty was due to penetration of high electric gradients into the electron stream exciting the ion source plasma. This alused a very hashy (lluctuating plasma density in tho megacycle frequency range) im source density and a divergent ion heam. An increase in plasma density corresponding to increased accelerating polontials eliminated this effert.

'The close approximation of computed to experimental values found in these mensurements $\left(V^{1 / 2}=c_{1} d^{2}\right.$ and $\left.I=c_{2} V^{3 / 2}\right)$ shows that the charge particle temperature effects are small. and strongly implies that there are no significant plasma oscillations which could causc signiticant changes in effective particle mean energy.

The validity of elementary ion rurrent theory for ion source evaluation has its limitations. One of these. which provides a real limit of an olsccure nature to the voliage gradient possible with ion sources, is the electric breakdown that uccurs when a limit is reached. T'he maximum potential gradient that con be maintained for a wide variety of collditions for one highly developed high current ion serurce for uranium isolope separat ion (the Calut ron) is af $\mathrm{kV}\left(\mathrm{m}^{-1}\right.$. Alowe this value, high vollage breakduwn begins in the thershold sense. for reasons described in Sere. IV. This limit in soltage sralient changes ("hild's law to the novel form $I_{\max }=$ $K^{\prime} V^{-1 / 2}=K^{\prime \prime \prime} d^{-1 / 2}$. 


\section{ION BEAM ACCELERATION REGION}

\section{A. Physical Processes}

The ion beam is accelesated in a geometry shown in Fig. 2, by high potential gradients from the ion source menuscus in the presence of a neutral gas density near $10^{1: 3} \mathrm{~mol} / \mathrm{m} /$. This neutral gas resules primarily from incomplete ionization of the ras passing through the plasma. A neutral gas in the acceleration region can be important in ion source performance not only because of ion beam scattering. which is usually small (alihough charge exchange produces a strong neutral particle beam). but also because of the formation of large circulating (ur equipotential surfices) elect ron currents in this region. The ion bean itsolf is relatively ineffective tioi ionization, since an elf tron of the same velocity. (o) usc familiar magnitudes, has an energy $V_{a}$ only of $V_{c}=\left(m_{l} / M_{l}\right) \cdot V_{l} \simeq 1 \mathrm{eV}$. where $V_{l}$ is the ion encrgy and $M_{1}$ is ion mass, argon in these experiments. Any electron formed in the gass by photoionization or electron scattering is highly ionizing hecause of its high mean energy in the ion acceleration region. The amplitude of electron cycluidal motion is $\mathrm{d}=2 \mathrm{eE} / \mathrm{m} \omega^{2} \simeq 1.4 \times 10^{-2} \mathrm{~cm}$. Magnitudes of $\mathrm{F}$ and $w$ for elect rons in the high current ion sources are near $\mathrm{F} \leq 60 \mathrm{keV}\left(\mathrm{cm}^{-1}\right.$ and $\omega=\mathrm{Ho} / \mathrm{mc}=10^{11}$ for $H=5(00)$ to $100(0)$ Oe. The electron maximum energy is $V_{e}=E d=1 \mathrm{keV}$ with an average value of the wider of $l(x)$ e $\mathrm{V}$. The mean transiverse electron velocity in the $E \times H$ field is approximately $\bar{v}=r \cdot F / H \simeq 10^{9} \mathrm{~cm} \mathrm{~s}^{-1}$. and the energy of the elect roms in the stream consistent with this velucity is approximately $\mathrm{F}_{\text {Irimon }} \simeq 3(\mathrm{M}) \mathrm{eV}$.

The elect rons formed in the ism beam atceleration region caluse further ionization in the neut rat gas. and large eurrents may he formed in electron. conserving svitems. This stroam is esporially troublesome for multiple (pilrallel) ion beam sources. thus mons st rat anems have been avolved in reduce inter-ion beam elfects. Tleser motherlo ion. sist exsentialle of eliminating circulating clectron corrents by formation of potential gradients $\mathrm{F}$ in the clircetion of the magnetic fiteld that allow the currents to lowe the system. The geometrical problem of inserting $H$-directed E voctors in the ion buam acceleration region generally increises ion beam sontres sepolation in multiple systems to approximately sme-third of the $H$-directed longt hot the iun sources.

A typienal offect of the rise of siveril parailet ion sources is ion beam deforusing which is duc to both the large circulating currents and the sectudiary eflecets of equantitien of ients being formed in the high electric gradient region. in particular, high woltage arcing and sparking. Extreme conditions ran al:ect ioin suurce electrical stability.

Considorations involving electron multiplication in tho acceleration regrion (which are givestionable bocause of the high velocity and low density expreded for the accelerating region transverse electron (urrents) have been generally validated by inrreasing and decreasing electron loss rate by eleci rodes which change loss rates with single and multiple ion beam geometries. No beneficial effects of these currents. such as decreasing ion space charge elferets. have been found. Factors of 2 on stable and well-focused ion beam production have resulted from small rhanges in slect rode geometry in the light of these considerations. Conversely, ion sources can be made inoperable simply by use of electronconserving fields in parallel ion source assemblies.

\section{B. Ion Accelerating System Interaction with Ion Source}

The accolerating sistem of the ion source has a double function: (1) focus the ion out put of the ionic plasma. which permits focusing at the ion beam collector, and to accelerate a high ion current from the plasma. These two factors are not independent: variations in potential gradient at the plasma surfare causes changes in curvature of the meniscus that results in a different focusing function for the elcctrostatic lens set up by the accelerating system. For this reasen. it is not possible to calculate in a simple way an ion beam focusing system or to design a sistem that will work for any given tipe of plisma of for any mignetic field. Acceleration svistem geometries are developed empiricalls.

Misimum produrtion of ions from any given type of arc refuires that the potential gradient at the surfare of the are can be no greater than a critical value given be ion diflusion current in the source phasma. langer values will incite ion souace plasma instabilities tseo soco. C). Because this potential yradient dotermines the position and shape of the moniscus for any ion beam source density and

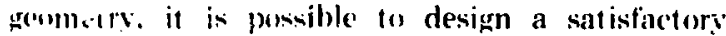
forusingr sistem using control of electrode voltage and sparing.

\section{Ion Souree Current Limit Across the Magnetic Firld}

The plisma of the ion source is optimized for (1) stabilits. II promit formation of a sharply forused ion beint: (2) temperalure. to specify the 
quality of the ion beam: (3) thickness and density (consistent with st ability), to maximize ion beam for a given supply of source gas: and (f) to minimize erosion of the surrounding apparatus. Controls are cat hode temperature and voltage (for plasma excit a$t i m$ cont rol), and voltages required for accelerntion of the ion beam to maximum ion current values. Formation of a stable ion beam plasma is important for magnetic focu: ing reasons, because a high density ion heam must be neutralized. first to form a heam plasma meniscus, and second to avoid ext reme space rharge disturbance of ion trajectories. Becaluse of long migration distances of electrons, stable ion beam plasma is noar the potential of the most positive electrode arcessible to the ion heam. Very long operating periods for ion beam production are made possible with these cont rols which reduce changes due to erosion, etc., in a complex system.

An optimized ion sururce may produce large controlled changes in ion beam currents up to limits on electric gradients set by acceleration region processes previously outlined, the most important of which is the maximum potential gradient. * Higher yradients incite sparking flurries due to mechanisms which are not completely understond. although a qualitative argument can he made from a descrip. tion of plasma structure as follows. The internal structure of the ion source plasma consists of a collimated high temperat ure elect ron stream coming directiv (with many small angle collisions) from the cat hode. On this is superposed the ambipolarly dif. fusing ionic plasma, circulating in a direction noraral to $H$ with a velesity magnitude $v \simeq \mathrm{cE} / \mathrm{H}$. I onization of the gas entering the plasina is conserwitive, with motion increasing the plasma thickness bevond the collimated electron st ream in a direction consistent with plasma polentials which are more nowative toward the center (the diffusing elect rom source). Elect rons are essentially trapped in an oscillating volume along $H$. therefiore anv elect rical or plasma geometry change that reduces the mean diffiusion velocity normal to $H$ and $F$. which permits draining of electrons from the plasma. results in us. cillations. One such change is penetration of the meniscus position-sen-itive, and thus relatisely unstable, ion heam acceleration potentials into the primary eleciron stream. coupling plasma density with heam space charge effects. Anothor is an increase in plasmo thickness that forces the electron to

*This maximum gradient, as will be scen, depends an s'ometry to some extent. John Luce, L. L.L.. was able to increase the maximum gradient value from

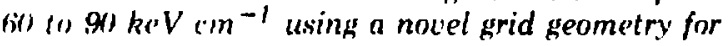
irin serurce's. increase the transverse dilfusion velocity by a hash (radiofrequency oscillations with a wide frequency band) mechanism. Thus, if plasma density and temperature are increased by energy and gas flow rate cont rols, the plasma thickness increases beyond the experimentally sptimized point. Hash is incited. The internal polential gradients change sign and magnitude with different current direction distribution to the ion heam source meniscus. The ion bean changes direction due 10 the different symmetry of the meniseus. The ion beam diverge, becaluse of a change in meniscus position due to the sometimes energetic ion plasma hash. The ion beam plasma is less completely neut ralized because of un. stable ion currents. and so it diverges because of internal space charge potentials.

The ion source plasma, ion beam acceleration region, and ion beam plasma are sufficiently connected hy potential distributions and charge Hows that they should be considered as a unit. As an extreme exanple, the ion heam may impinge on an electrode. such as an ion collector, several meters from the ion source. Potentials on this collector hav' been seen wo affect ion source performance through the ion beam plasma over this long path and through the acceleration region.

\section{1}

\section{Ion Beam Plasma}

The ion beam firom a high intensity im snurce must be electricnlly neutral both for heam diverences reasons and to provide a minimum acceleration electrode spacing for maximum ion ccirrent (I rdd $^{-1 / 2}$ ). The ion heain plasma may be formed by the weakly ionizing ion boam at ion encrgiss $>10.20 \mathrm{keV}$, and this is the simplest and nost used method if there is a sufficient amount of easuly ionized and preferably electronegative gas in the ion heam trajectory. Formation of the ion beam plasma attenuates ion beam rurrent, but the mean lifo of plasina ions and electrons for gus pressure reasonably optimized $\left(p \simeq 10^{-5} \mathrm{~mm}\right)$ is sufficiently long that the net attenuation is not large. The relative ense of this method of forming ion heam plasma has reduced interest in ion beam plasma physic's, except where a minimum of residual space charge is important, and when lower particle velocity ion beams are in question.

Methods ol' producing additional neutralization are as follows.

1. (Ise of an intense source such as a do arc to produce photoionization of residual gas in the ion heam volume. 
2. lat of how ionization potential gases in the beam plasmal.

3. Secondary amission be ion beam bombardment of comtainer walls.

1. Thermenelectrive emissiom of container walls or iuxtaposed tilamonts.

These methods have all been shown te have a signili. callt and sometimes very important flor low ion hean particle emersul eflect on ion beam particle trajecturies. be reduction of space charese.

There are added comsiderations to condition at choice of neut ralization means.

1. Negative charges in the plasma do not move vers lar alomis the beame (normal to $H$ ).

2. The plasma is normal in covery way, includinn resenance frepuldecion. a Maxwellian temperature sistrihution. space charge porential positive with respect to container walls ('ypically 2 eV). A search with a wase analszer failed to locite any but thelmal low amplitude frequencies characteristie of lismal densill and ienn species.s.

3. Plasma diensity is an order of masnitude wreater than averige ion beam delixity.

4. The electron temperature from lamsmuir molle measurements is remarkahly high: 2-1 eV fur a :30 kel argen ion heam.

5. Pasma purential is relatively contitant aiong $H$ and. from langmuir probe measurements. approximattely expull 10 the electron tomporature in eloct ron volts.

is. The plasma spare charpe is a sellsitive indieature of the slability (small $\mathrm{rl}$ amplitudel of the ion heam it seif. The presence of ion heram density

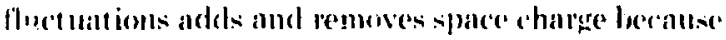
of different mobitition of ions and elect rons, which

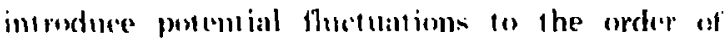
masenitude of these that would be pressent with nis mentralizing platsma. For example. for arders of magnitude with an argen ion beam. $F^{\prime \prime} V=3 \times 10^{-2}: F=d V / d x=0.2 . x$ esa where $x$ is distince. This will resull in strung ion beam diversence. which is olserved with an unstibls ion siltire.

An example of the usefulness of these observat iors wis found in the development of a miss analviser.

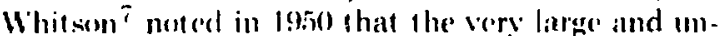
iform magnetir liekls avalible with the Calutholl coulde be used to derermine the mass of heavs isotopes simply by letting a pulse of ions circulate for al bong timo in the mannetic lield. A low voltinge thence. small radii fir ion trajectoriest ion source wal- const ructed. using a short chop in a contintouss

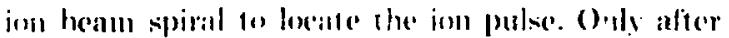

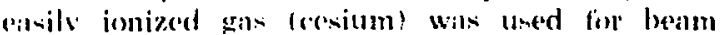
phisuma formation did the devire work well for boim pulso pa-ition measurement. All methode other than "hares scantering for beam neutralization failed to forall the gap because of its clusure by space charne effects.

\section{MAXIMLM ION CURRENTS FROM A PI.ASMA}

\section{A. Ion Currents}

An evaluation of ion currents fromn an ionized sas (an be made more simply by exprerimental than by analvical means. This is due to a lack of detailed knowledge of actual ion and electron temperaturon and internal potential and density gradients. Such an experimental evaluation is sisnificant if the ion current: are controllable as, for example. samplen emitted through small collimating slots, and if the currents are comnected with a well-understoul phvisical situation.

\section{B. Large Probe Measurements}

An experiment was conducted in the lisht of the

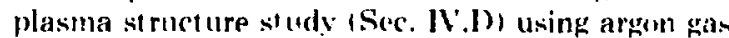
and electron beam excitation or heating of the plasma in a magnetic field. Larue probes collocted saturation ion currents parallel to $H$ through an ion current collimation sost and nornal of $H$ thrownh a second slot on a protected probe tsee Fig. 1). Iols moved freely (parallel o $H$ ion a stable plasma ir one direction ( $I=$ ne $\bar{u}$ ) and slowly (across $H)$ in the other: the rate depended on the self-collision periud 7. the plasma internal electric gradients $E$. and the magnit ude of $H$. The object ive of the analysis wis 11 establish swstematic trends to enhance a qualitative understanding of the diffusion processes als wril as to obtain magnitudes for ion currents. The magneide ficld was used to (istablish a currdinate system for diffusion velocity measurements: it was usod beciallse plasma healing he electron currents is most efficient in the oscillating colume cilsily established by elect rockes in a mannetic field. Also, of course. ion corrent magnitudes have signilicance in ion sourer andirises be phesical moans.

Several questions remain.

1. Det hash pherwmena enhance ion diffusiom across $H$ and thus incroase the ion current magnif ude?"

2. How are im currelits along and across $H$ actilalls molated"?

3. What are the upper limits for iun currents from a pla-ma into an ion beam? 
Two probes which collect $I_{x}$ and $I_{2,}$ resperetively mitallel and normal to $H$, were juxtapensed. so that tise ratio of parallel to normal (perpendicular) currents (with relation to the magnetic fiedd veretor) sulfice to covaltatic the velecity ration in these dires. fims. The apparal us simply consisted at a geometw designed to generate a plasma $0.25 \times 2.0$ com in corss sertion normal to $H$ and $20-6 m$ long in the direction (1) $f l$. An argon gas suppoiv on ohe side and a cacuum int the ofher $\{1.27-(\mathrm{cm}$-wide inening $)$ permilled gats silp phe and ale(ess, lility. (One end of the plasma was dire'tly dexponed to a cathode tilament flantalum! at : int rollable temperature and voltage so that plasma heatting by electron interaction could be stupplied wish 010 I $\mathrm{kW}$ af power in the form of an electron: corrent trem the filament. 'Tho anti-cathode end of the plasina terminated through a $1.0 \times 0.16 \mathrm{~cm}^{2}$ rpening on a colle tor phate at a comt rolled postemtial. The side of the plasma oxposed to taletum wits also

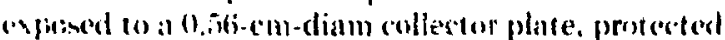
he a ring al the same pultential. Conventional corremt and voltage cireuts permsted ensterol.

\section{Currents Along and Aeross the Magnetic l'ield}

Figures 6.5 summarize the probe ion currents for - itlurillion conditions over the control rampe of the plasma currents, limited on the lower pressitule and puwer side by plawmat dxtinction. The cont rol renge" included both stable and hashy sonditions as evaluated by relillise magnitudes of ri current anplitudes on the elect modes. Stability is eonsistent in greneral with patrallel. (to $H$ ) lo-non:mal current rittios marar 2.2.

In Fig. of nute the remarkable constamey of the ration $I_{11} / I_{w}=2.2$. where $1 \mathrm{is}$ parallel and $w$ is mormal 1: hi. Ialrger villues are consistent with a higher dengee of ionization of the plastlta resulting from in.

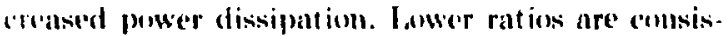
rent with lower temperatlure and density plisma for which the interral colectrice aredients, resulting from

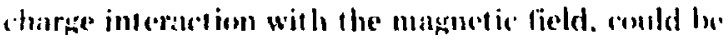
larprer.

\section{1). Conclusions}

1. The effect of plasma osciliations on diffusion it russ the magmetic tield is apparently small since the rattion of current along $H$ (1) areross $H$ is indepen.

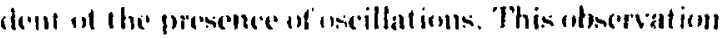
is consistent with results in Fig. 7 in which high ex-

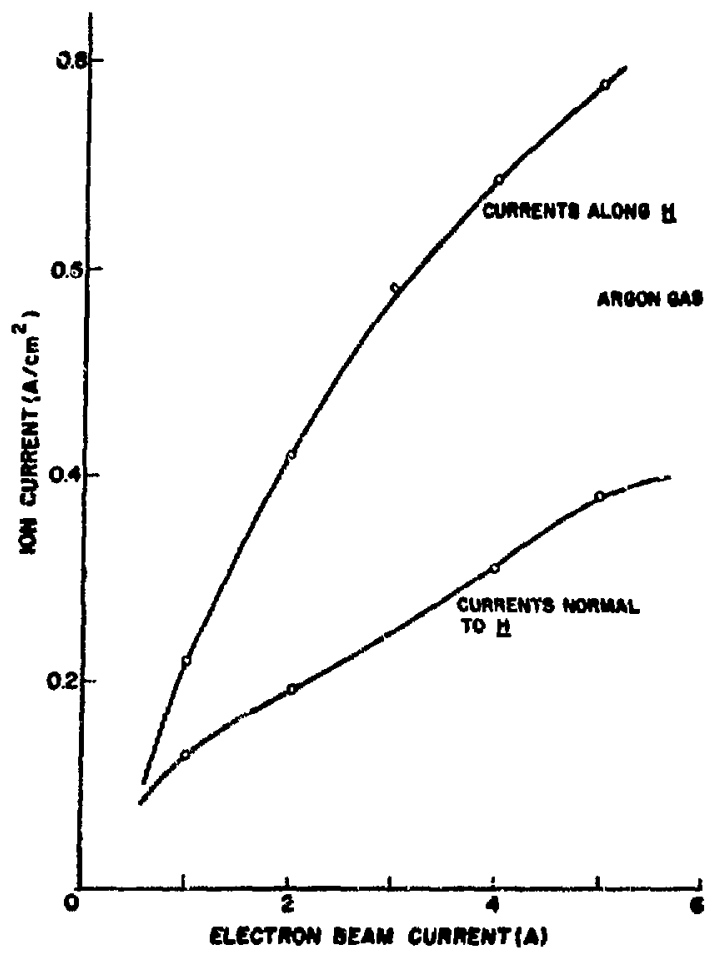

Fig. 6.

Imm current is electron beam current.

cilution currents, which commonly cause plismit hash. actually decroase the relative current acruss $H$.

2. The constancy of the ration $\pi / \bar{w}$ restuits in the novel rolationship hetween currents" parallel to $\left(I_{\text {" }}\right)$ and normal ${ }^{\prime}\left(I_{w}\right)$ the magnet ic ficld $H$ :

$$
\frac{I_{u}}{I_{w}}=\frac{\bar{u}}{\tau} \frac{m}{2 E_{z}}=\frac{K n}{T E_{z}} \approx 2.2 .
$$

Lark of knowledge of the dependence of ' $T_{\text {iun }}$ and f, om plassma density and power dissiparion prevents further recluction of this dat a.

3. Tho degree of iomization of the pinsma. which should affert diffusion in a large way due 10 the eflenef on the ion coulomb collision period $\left(\mathrm{ra} \%^{-4}\right)$. has litfle effect on piasma currents. This indicates that the plasma ion diffusion processes are in a domain of relative independence of the magnetic field. exc'plyt in a sc condary way by the dependence of $F$, on $H$. This conclusion depends on Chapman's factor $\left(1+\omega^{2} \tau^{2}\right)^{-1}$ on diffusion velocity." wher 


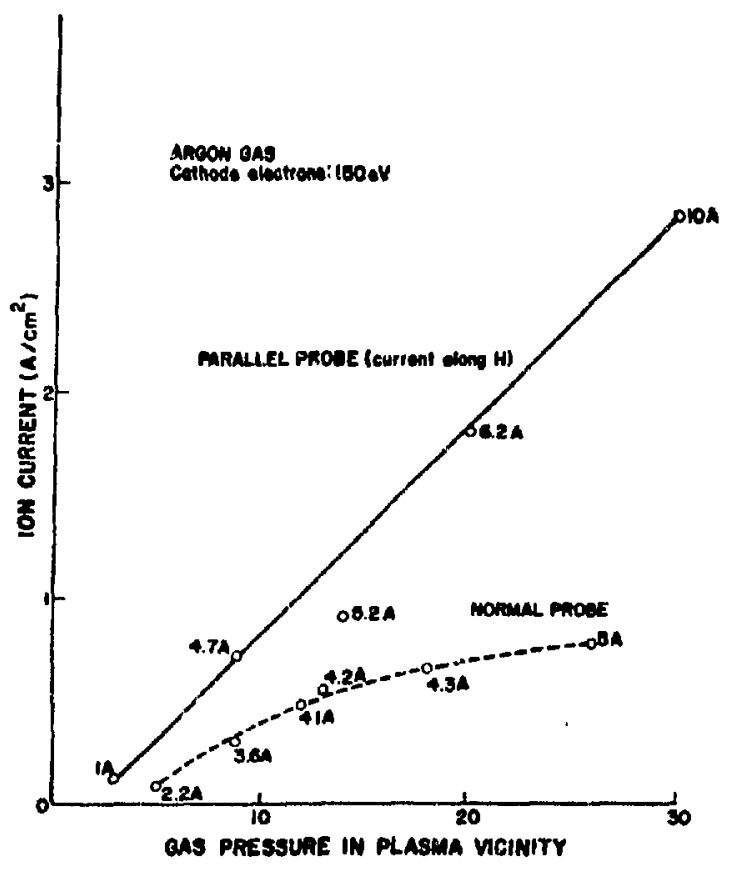

Pigs. 7.

lom current is gat pressure in the ion stource.

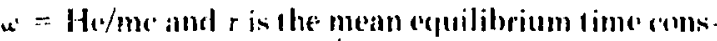
tant fin solf-interaction. ${ }^{4}$

i. The essentially linear rolationships, shown in Fijs. $T$, between plasma gas pressure and rorrents from a plasma. exhitit mo definite limitation on currents from a plasma in a magnet ic fichl. Masmomi semsitivits bo exciting cleceton curremt conditions. al familiar phenomenom. is also illustrated in Fig. 8.

\section{V'I. RLMARKS}

Although there is molhing sorprising in this report. it cill be helpful in ien heatur considerat ions for conn rentional and nusel appliciations. Deselepment al ian beam devices remains latrely an experimental elfort. The ideass stummarized in this report helped to correlate mitne ("illutrors olservations in the development of verv simple high density ion shures and in the understanding of ion beams alted soluree. now heing used in mans plates. The general prollem is that of formingre a denst'. uniform. stables plasilla with mest of the excitat iom energy alpleatring an heat.

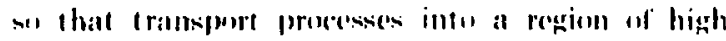

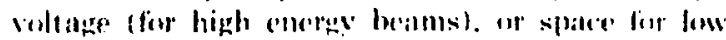

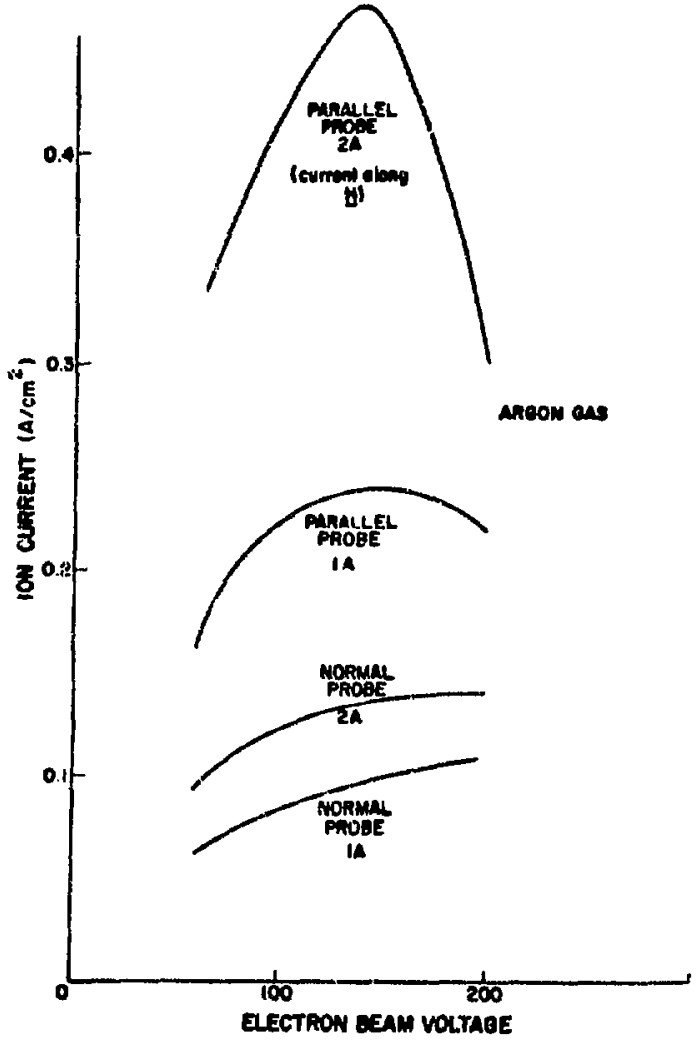

Fig. 8.

hin current es olectron besm coltage for 1 and IA ifectron beam current.

energy neutral beams, are optimum for the particular situat ion. It is not necessary to involie a hash morhanism fur diffusion acresss a ventor field $H$ and.

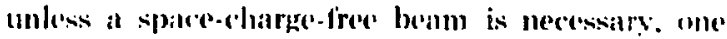
trespuenly finds that the hash does little but increase paransitic losines in efficiency. The beam formation

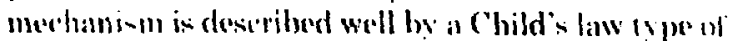
copation: ion beam neutralization has not been a prohlem. Details of ion sourese and beam plasma phosics are onle determined with diflicults: much rentuins to be dime in this field.

\section{A(KNoWI,WI)(MMNTIS}

(. F. Barnerl and o. S. Lace have eontributed many experimemtal facts, anteilical discussions. and encouragement in this lask of understancitng inol silleres phosie's. 


\section{REFERENCES}

1. A. Guthrie and R. K. Wakerling, The ('haracteristics of Electrical Discharges in Magnetic Fields (McGraw-Hill Book Company, Inc.. New York, 1949).

2. S. Chapman and T. Cowling, Mathematical Theory of Non-l/niform Gases (Cambridge University Press, Cambridge, 1939) 2nd Ed., p. 322. See also S. Glasstone and R. H. Lovherg. Controlled Thermonuclear Reactions (D. Van Nostrand Company. Inı.. New Yurk. 1960). Chap. 12.

3. C. L. Longmire and M. N. Rosenbluth. "Ditfusion of Charged Particles Across a Magnetic Field." Phis. Rev. 103. 501 (1956).
4. I. Spitzer, Jr., Physics of Fully Ionized Gases (Interscience Publishers, Inc.. New York. 19:56), p. sti lit.

5. C. B. Mills and C. F. Barnett, "High Intensity Ion Source," Rev. Sci. Instr. 25, 1200) (1954).

f. C. B. Mills, University of California Radiation laboratory. unpublished work, 1945.

7. William Whitson, Oak Ridge Notional l.ihuratory, unjublished work, 1951. 